\title{
Morphological, Biological and Antigenic Properties of Neisseria gonorrhoeae Adapted to Growth in Guinea-Pig Subcutaneous Chambers
}

\author{
By C. W. PENN, D. SEN, D. R. VEALE, N. J. PARSONS AND H. SMITH \\ Department of Microbiology, University of Birmingham, P.O. Box 363 , \\ Birmingham B15 $2 T T$ \\ AND K. WITT \\ Microbiological Research Establishment, Porton, Wiltshire
}

(Received I4 April 1976; revised 9 June 1976)

S U M MA R Y

Gonococci (strain BS3) passaged three times and harvested directly from plastic chambers implanted subcutaneously in guinea pigs were compared with the parent strain (BS) grown in vitro. The strain grown in vivo produced smaller colonies than that grown in vitro and when examined directly in chamber fluid was sometimes not pilated. It was more resistant to the bactericidal action of human serum and more infective for guinea-pig chambers. In gel diffusion, extracts of the organisms adapted in vivo and cultured once on agar appeared to contain one or two antigens that were different from those in extracts of the in vitro grown organisms; and on polyacrylamide gels, electrophoresis of similar extracts showed one or more protein components for strain BS3 which were not seen for strain BS. Gonococci grown in guinea-pig subcutaneous chambers appear to be suitable for studies on the determinants of gonococcal pathogenicity.

\section{INTRODUCTION}

Many of the difficulties encountered in attempts to identify the determinants of the virulence of bacteria stem from the fact that virulence is detectable only in vivo and that it is markedly influenced by changes in growth conditions due to selection and to phenotypic change. The genetic information which determines virulence may be expressed fully only during growth in vivo. When bacteria are removed from animals and grown in vitro, there is usually a loss of virulence. Hence, although organisms grown in vitro are readily studied, they can be incomplete in their virulence determinants. Thus, for problems of pathogenicity that have not been solved using cultures in vitro, a study of bacterial behaviour in vivo might provide the answers (Smith, I972).

Many questions about gonococcal pathogenicity are unanswered, and gonococci in urethral pus appear to be different biologically and morphologically from gonococci grown on laboratory media. Organisms from urethral pus infect humans more readily than do gonococci grown in vitro (Mahoney et al., 1946), and they are more resistant to killing by human antibody and complement (Ward, Watt \& Glynn, 1970). The walls of organisms from urethral pus are smoother and have better organized layers than type I or 2 organisms (Kellogg et al., 1963, 1968) grown in laboratory culture, and pilation is much reduced (Novotny, Short \& Walker, I975). Unfortunately the numbers of gonococci that can be isolated from samples of urethral pus are too small for detailed investigations. However, 
another source of organisms grown in vivo has become available. Arko (1972) described perforated plastic chambers implanted subcutaneously in laboratory animals which could be infected with gonococci. Veale et al. (1975) produced consistent infections (about $10^{6}$ organisms per ml chamber fluid, persisting for 20 to 40 days) in modified Arko-type chambers in the presence of a polymorphonuclear inflammatory response similar to that seen in human urethral infection. The chamber infectivities of different strains (small-colonyforming AS and BS, large-colony-forming AL; Veale et al., 1975) paralleled the infectivities for humans of similar colony types described by Kellogg et al. (1963, 1968). Furthermore, the infectivities of strains AS and BS were increased about I00-fold by three passages through chambers, showing that selection and/or phenotypic change had taken place.

In this paper we compare the thrice-passaged BS strain (called BS3) isolated directly from the chambers or after one subculture in vitro, with the parent BS strain grown in vitro. A preliminary report has been published (Penn et al., 1975).

\section{METHODS}

Gonococcal strain grown in vitro. This was the pilated, small-colony-forming strain BS resembling Kellogg type 2 and infective for guinea-pig chambers as described by Veale et al. (1975). An $18 \mathrm{~h}$ culture on modified Amies \& Garabedian medium (see below) was suspended in Trypticase Soy Broth (TSB; BBL) and mixed with an equal volume of $2 \%(\mathrm{w} / \mathrm{v})$ proteose peptone no. 3 (Difco) containing $16 \%(\mathrm{v} / \mathrm{v})$ glycerol; $0.5 \mathrm{ml}$ portions were frozen and stored in liquid nitrogen (Ward \& Watt, 197I). In some experiments thawed samples were used directly: these organisms are designated BS. In others, they were subcultured once on agar before use; these are designated BS (agar).

Media. These were haemoglobin agar, described by Veale et al. (1976), and a clear agar medium (AG agar) modified from that of Amies \& Garabedian (I967) by Veale et al. (1975).

Subcutaneously implanted guinea-pig chambers. Male Dunkin-Hartley guinea pigs (grade 2; Olac, Banbury, Oxfordshire; $600 \mathrm{~g}$ ) received two or four chambers (4 to $5 \mathrm{ml}$ ) which were implanted, inoculated and sampled as described by Veale et al. (1975).

Gonococcal strain grown in vivo. A suspension in TSB $(0.2 \mathrm{ml})$ containing about $10^{3}$ viable strain $\mathrm{BS}$ organisms was inoculated into a chamber. Seven days later chamber fluid was removed, diluted $\mathrm{I}: 1000$ with TSB, and $0.2 \mathrm{ml}$ of the diluted suspension was inoculated into a fresh chamber implanted in another animal. Two days later the procedure was repeated with a $1: 100$ dilution of the chamber fluid. One day after inoculation of the third chamber, chamber fluid ( 2 to $3 \mathrm{ml}$; about $2 \times 10^{6}$ organisms $\mathrm{ml}^{-1}$ ) was removed, diluted $(\mathrm{I}: 20)$ with cryo-protective medium (see above) and frozen in liquid nitrogen. In some experiments the thawed culture, $\mathrm{BS}_{3}$, was used directly; there was no detectable loss of viability on freezing and thawing as indicated by viable counts on thawed samples taken over 18 months. In other experiments BS3 organisms were cultured once for $18 \mathrm{~h}$ on haemoglobin agar: these are designated BS3 (agar). In some, the last guinea-pig passage was repeated to provide BS4 (chamber) organisms; these were used immediately.

Observations of pili by electron microscopy. Suspensions of gonococci [BS3 (agar) and BS (agar)] in water (about $\mathrm{I} \times \mathrm{IO}^{8}$ organisms $\mathrm{ml}^{-1}$ ) were mixed with an equal volume of $2 \%$ $(\mathrm{w} / \mathrm{v})$ potassium phosphotungstate, $\mathrm{pH} 7 \cdot 2$, and drops were placed on carbon-coated formvar grids. Excess liquid was removed by touching the edge of the grid with filter paper. The sample was dried in air and examined immediately in a Philips EM 20I electron microscope at $80 \mathrm{kV}$. 
For observations on BS4 (chamber) organisms, a drop of infected chamber fluid was placed on the surface of $\mathrm{I} \%(\mathrm{w} / \mathrm{v}$ ) Noble agar (Difco) in phosphate-buffered saline (Dulbecco A solution; Oxoid) $\mathrm{pH} \mathrm{7.2} \mathrm{(PBS).} \mathrm{A} \mathrm{grid} \mathrm{was} \mathrm{inverted} \mathrm{on} \mathrm{the} \mathrm{drop,} \mathrm{and} \mathrm{when} \mathrm{the}$ fluid had been absorbed into the agar (about $5 \mathrm{~min}$ ), the grid was removed and dried in air. It was treated with $\mathrm{I} \%(\mathrm{w} / \mathrm{v})$ potassium phosphotungstate, $\mathrm{pH} 7 \cdot 2$, and excess liquid was removed as described above. As a control, BS3 (agar) organisms were suspended in chamber fluid from a non-infected animal and treated in an identical manner. Because of the large amount of protein and other material in the chamber fluid, electron micrographs were not clear; nevertheless pili were observed on organisms in the control preparations made from five different samples of gonococci and chamber fluid.

Test for resistance to bactericidins in fresh human serum. Fresh human serum $(0.5 \mathrm{ml})$ and gonococcal suspensions $\left(0.05 \mathrm{ml}\right.$ TSB containing about $\mathrm{I} \times \mathrm{IO}^{5}$ gonococci) were placed in $2 \mathrm{ml} \mathrm{screw}$-capped polypropylene ampoules (Sterilin, Richmond, Surrey) and incubated in $5 \% \mathrm{CO}_{2} / 95 \%$ air at $37^{\circ} \mathrm{C}$. Samples $(0.05 \mathrm{ml})$ were withdrawn for viable counts after $\mathrm{I}, 2$, 4 and $7 \mathrm{~h}$.

Estimation of approximate minimal infective dose (m.i.d.) for subcutaneous chambers. BS3 and $\mathrm{BS}$ cultures were thawed rapidly at $37^{\circ} \mathrm{C}$ and immediately diluted, serially Io-fold, in warm TSB to give approximately $2,20,200$ or 2000 organisms in a $0.2 \mathrm{ml}$ inoculum. The doses were based on previous viable counts on thawed samples of the same stock cultures and were checked at the time of the experiment by further viable counts. Portions $(0.2 \mathrm{ml})$ of inoculum at the ' 20 organism' dilution were plated out, and contained 19,15 and 22 (mean I9) BS3 organisms and I6, I I, 23 (mean I6) BS organisms. Animals with four chambers received both strains at two dose levels in separate chambers. Viable counts on chamber fluids were done after $24 \mathrm{~h}$ and 7 days. The approximate m.i.d. was the lowest inoculum that produced significant viable counts $\left(>50\right.$ gonococci $\left.\mathrm{ml}^{-1}\right)$ at $24 \mathrm{~h}$.

Examination of surface antigens by gel diffusion. Organisms grown for $20 \mathrm{~h}$ on haemoglobin agar were suspended in TSB to a concentration of $5 \times \mathrm{IO}^{10}$ organisms ml-1. After mixing for $\mathrm{I}$ min in a vortex mixer (Fisons Scientific Apparatus) with $3 \mathrm{~mm}$ diam. glass beads, suspensions were centrifuged at $1500 \mathrm{~g}$ for $20 \mathrm{~min}$. This treatment did not cause appreciable lysis or killing of the gonococci: more than $90 \%$ of the gonococci were intact as shown by electron microscopy and by the ratio of viable to total counts of approximately I: $I$. The supernatant solution was used for gel diffusion. Serum was obtained from guinea pigs which had carried chambers infected with BS3 for about 6 weeks; it was concentrated fourfold by freeze drying and reconstituting with distilled water. It was adsorbed by adding $5 \times 10^{10}$ strain $\mathrm{BS}$ organisms per $\mathrm{ml}$ serum and, after standing at $4{ }^{\circ} \mathrm{C}$ overnight, removing the gonococci by centrifuging at $1500 \mathrm{~g}$ for $20 \mathrm{~min}$. Tests were performed in I $\mathrm{mm}$ thick $\mathrm{r} \%$ (w/v) Noble agar (Difco) in PBS, $\mathrm{pH} 7 \cdot 2$, containing $0.01 \%$ thiomersalate, in which $3.5 \mathrm{~mm}$ diam. wells were cut $2 \mathrm{~mm}$ apart. After $\mathrm{r}$ to 2 days gels were washed in PBS, dried and stained with $0.25 \%$ Coomassie Brilliant blue R250 in acetic acid/methanol/ water (Io:45:45, by vol.) (CBB); this solvent was also used for destaining.

Examination of extracts in polyacrylamide gels. Gels containing $6.65 \%$ (w/v) acrylamide and $0.35 \%$ bis-acrylamide in $0 . \mathrm{I} \mathrm{M}$-Tris $/ \mathrm{HCl}$ buffer $\mathrm{pH} 8.6$ were polymerized in $5 \times 75 \mathrm{~mm}$ tubes by adding $0.05 \% N N N^{\prime} N^{\prime}$-tetramethylethylenediamine and $0.005 \%$ ammonium persulphate. Extract $(20 \mu \mathrm{l})$ was applied to the gel and electrophoresed at $\mathrm{r} \cdot 0 \mathrm{~V} \mathrm{~mm}$ for $5 \mathrm{~h}$. Gels were stained overnight with CBB and destained in acetic acid/methanol/water (6:14:80, by vol.) for photography. 

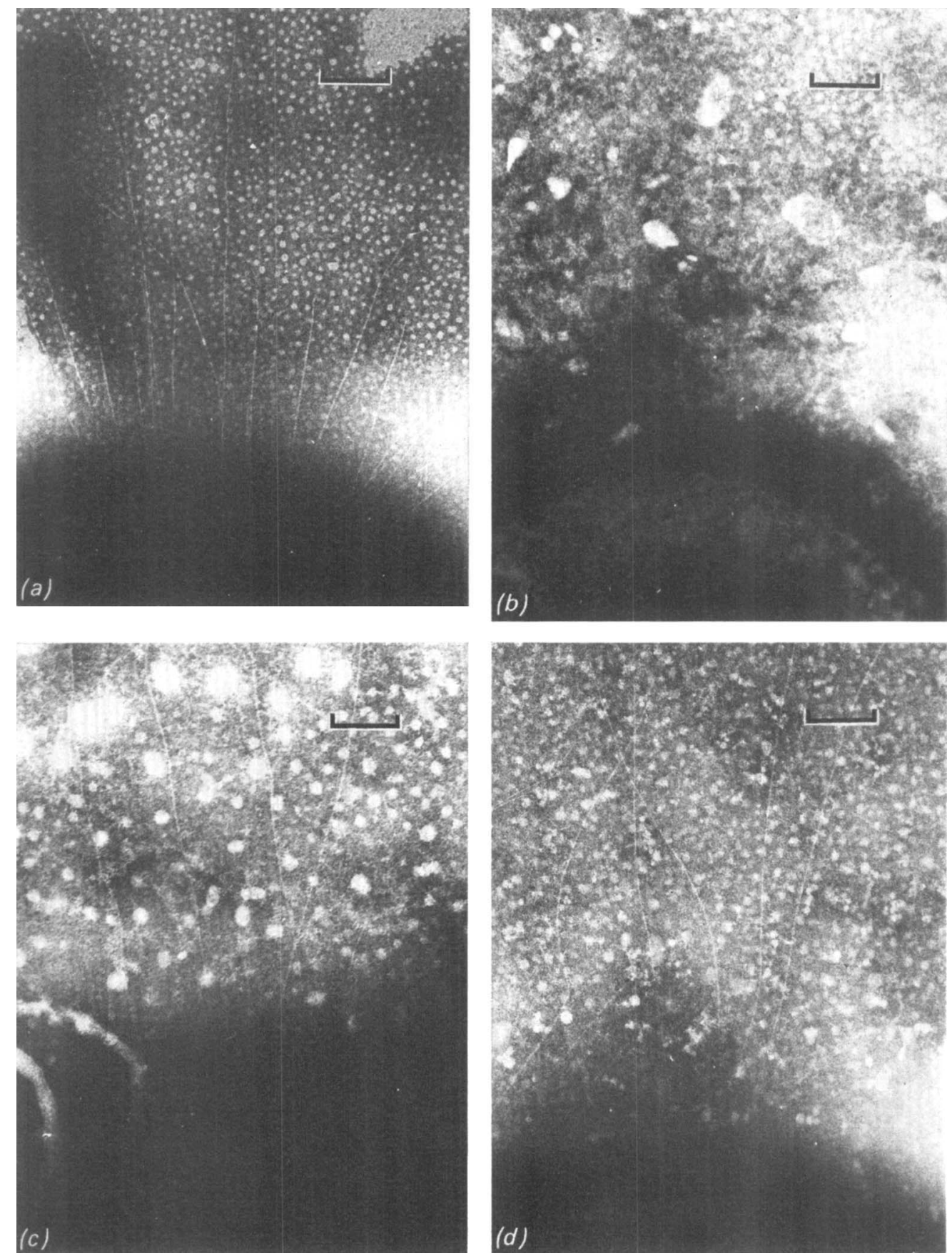

Fig. I. Pilation of gonococci (negatively stained) grown in vivo and in vitro. (a) BS3 (agar) organisms prepared from a suspension in distilled water; pili present. (b) BS4 (chamber) organisms prepared from infected guinea-pig chamber fluid; no pili observed. (c) BS4 (chamber) organisms from another chamber; pili observed. (d) BS3 (agar) organisms from a suspension in normal guinea-pig chamber fluid; pili observed. Bar markers represent $0.1 \mu \mathrm{m}$. 


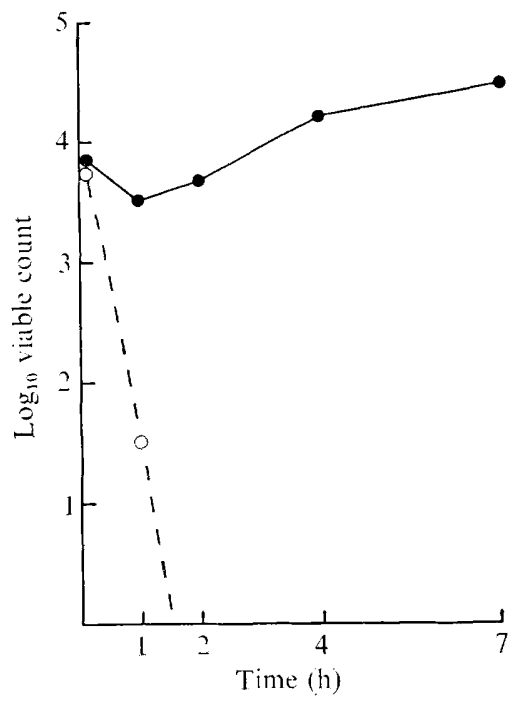

Fig. 2. The results of an experiment, typical of five, showing the effect of human serum on strains $\mathrm{BS} 3(0)$ and BS $(O)$. The line drawn for BS was extrapolated to zero through a reading of $<50$ at $\mathrm{I} \mathrm{h}$.

\section{RESULTS}

\section{Colony form}

After $20 \mathrm{~h}$ on AG agar, colonies of BS3 (agar) were smaller ( 0.5 to $\mathrm{I} \mathrm{mm}$ diam.) than those of BS (agar) (about $2 \mathrm{~mm}$ diam.). The small colonies of BS3 (agar) were of uniform morphology and showed no tendency to dissociate; the morphology persisted for at least five subcultures. Apart from their size, the colonies were similar and as described for types I and 2 by Kellogg et al. (1968).

\section{Pilation}

Both strains BS $_{3}$ (agar) and BS (agar) were pilated but observations on 100 organisms in four or five different samples indicated that at least $90 \%$ of the $\mathrm{BS}_{3}$ (agar) organisms bore pili whereas less than $50 \%$ of the Bs (agar) organisms did so (Fig. I $a$ ). In contrast, pilation of BS4 (chamber) organisms was variable: pili were not observed on gonococci (Io organisms examined from each chamber) from five of nine chambers (Fig. $\mathrm{I} b$ ), were sparse on organisms from one chamber, and abundant on organisms from three chambers (Fig. I $c$ ). In five control preparations of BS3 (agar) organisms suspended in five different chamber fluids, pili were visible on gonococci (Fig. I $d$ ), although they were not as clear as when the organisms were suspended in distilled water (Fig. I $a$ ).

\section{Resistance to bactericidins in fresh human serum}

Strain BS3 was more resistant than strain BS to killing by five different samples of human serum. The results of a typical experiment are shown in Fig. 2. Strain Bs3 multiplied after a short lag phase and in four of the five sera continued to do so over the $7 \mathrm{~h}$ period of observation. Strain BS could not be detected ( $<50$ organisms $\mathrm{ml}^{-1}$ ) in four of the five sera after $\mathrm{I} \mathrm{h}$, and in the remaining serum it was reduced roo-fold in $\mathrm{I} h$. In four experiments with different sera the resistance of strain BS3 was lost after one subculture on agar; it [BS3 (agar)] behaved similarly to BS. In four more experiments with different sera, fluid from 
Table I. Infectivity for guinea-pig chambers of strains BS3 and BS

\begin{tabular}{lccc} 
Strain & $\begin{array}{c}\text { Inoculum } \\
\text { (approximate no. } \\
\text { of organisms) }\end{array}$ & \multicolumn{2}{c}{ No. of chambers infected $\uparrow$ at } \\
BS3 & 2 & $2 / 2$ & 7 days \\
& 20 & $2 / 2$ & $2 / 2$ \\
& 200 & $2 / 2$ & $2 / 2$ \\
BS & 2000 & $2 / 2$ & $2 / 2$ \\
& 2 & $0 / 2$ & $2 / 2$ \\
& 20 & $0 / 2$ & $1 / 2$ \\
& 200 & $0 / 2$ & $1 / 2$ \\
& 2000 & $1 / 2$ & $1 / 2$
\end{tabular}

* Figures were based on viable counts done previously on thawed suspensions and checked by further viable counts at the time of the experiment (see Methods).

+ Counts greater than 50 viable gonococci per $\mathrm{ml}$ chamber fluid; usually they were $1 \mathrm{O}^{4}$ to $\mathrm{IO}^{6}$.

infected guinea-pig chambers was added to strain BS3 (agar) in an amount equivalent to that which was present with the inoculum of $\mathrm{BS}_{3}$, but this did not confer resistance to human serum.

\section{Approximate m.i.d. for subcutaneous chambers}

The approximate m.i.d. values for strains BS3 and BS were 2 and 2000 organisms respectively (Table 1 ). The value for strain BS is similar to that obtained by Veale et al. (1975). The m.i.d. was based on chambers infected after $24 \mathrm{~h}$. Two chambers apparently sterile after $24 \mathrm{~h}$ were infected with strain BS after 7 days.

\section{Antigens detected by gel diffusion}

The extract of BS3 (agar) formed a precipitation line near the antigen well with unadsorbed guinea-pig serum from animals having chambers infected with BS3. This line was not formed by the extract of BS (agar) (Fig. $3 a$ ). After adsorption of the serum with BS (agar), the BS3 (agar) line remained (Fig. $3 b$ ); however it disappeared when the serum was adsorbed with BS3 (agar). Sometimes a second faint precipitation line was formed by BS3 (agar) but not BS (agar) when serum adsorbed with BS (agar) was used.

\section{Proteins detected by electrophoresis on polyacrylamide gels}

A dense band was seen near the top of gels prepared from extracts of BS3 (agar) which was less mobile than the least mobile band seen on gels prepared from extracts of BS (agar) (Fig. 4). A faster-moving double band was seen in both gels but in the gel from BS (agar) the lower of these two bands was less intense than in the gel from BS3 (agar) (arrowed, Fig. 4).

\section{DISCUSSION}

Gonococci grown in guinea-pig chambers were different from those grown in vitro in all the properties examined.

The colonies of BS3 (agar) were smaller than those of BS (agar) although the form of both types was similar. The smaller colonies of the in vivo grown strain persisted on repeated subculture suggesting that a genotypic rather than a phenotypic change had taken place. Further investigations of the colony morphology are in progress.

When subcultured once on agar the gonococci from the chambers [BS3 (agar)] were strongly pilated, more so than the original strain. Observations of pili of organisms taken 


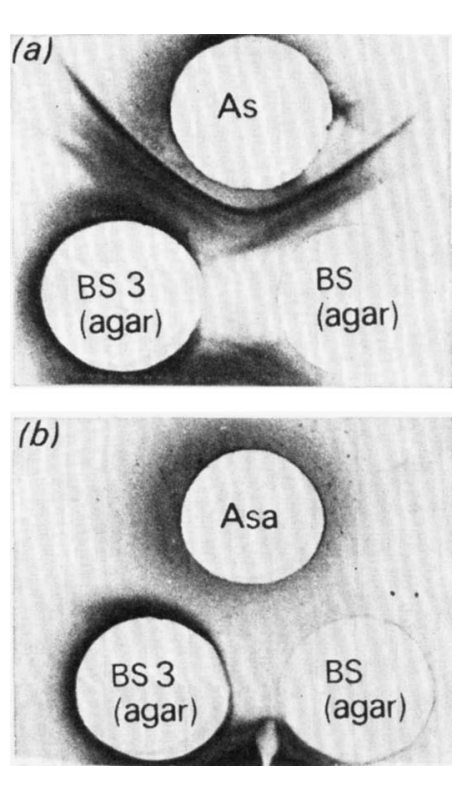

Fig. 3

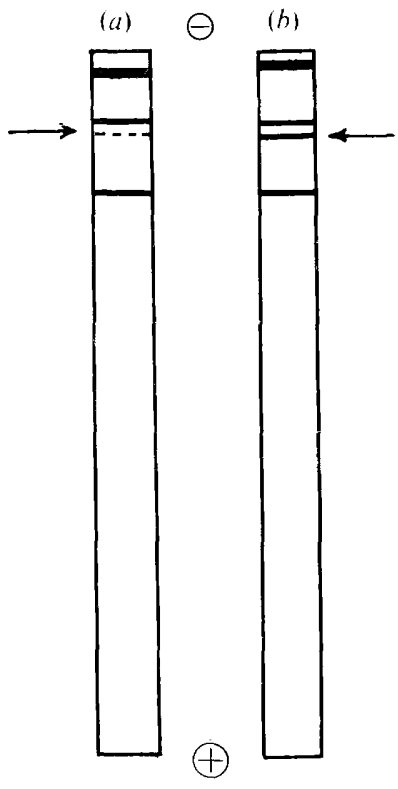

Fig. 4

Fig. 3. Gel diffusion of soluble extracts of strains BS (agar) and BS3 (agar): (a) against antiserum (As) from guinea pigs which had carried chambers infected with strain BS3 for about 6 weeks; and (b) against antiserum (Asa), prepared by adsorbing As with BS (agar).

Fig. 4. Tracings of polyacrylamide gels of extracts of (a) BS (agar) and (b) BS3 (agar), after $5 \mathrm{~h}$ at $\mathrm{I} \cdot \mathrm{O} \mathrm{V} \mathrm{mm}^{-1}$ and staining with CBB.

directly from chambers was technically difficult due to masking of pili by a film of macromolecules from the chamber fluid. Attempts to isolate organisms from chamber fluid for more critical examination failed because of the small numbers present and damage during processing. However, adequate controls in the presence of chamber fluid showed that pilation of the chamber-grown organisms was variable. In some chambers gonococci were not pilated and in a few pilation was abundant. The reasons for these differences in pilation are not clear but the relative lack of pili on chamber-grown organisms paralleled to some extent the observations on gonococci in urethral pus (Novotny et al., 1975).

The resistance of strain BS3 to fresh human serum compared with that of the strain grown in vitro was considerable. Furthermore, this resistance was lost after one subculture on agar and was not due to the small amount of chamber fluid included with BS3 in the inoculum since addition of chamber fluid to strain Bs 3 cultured once on agar did not confer resistance. These results parallel those of Ward et al. (I970) for the resistance of gonococci from urethral pus compared with that of the same strains after subculture. The resistance of gonococci grown in vivo to human serum may play a part in the pathogenesis of gonorrhoea on mucosal surfaces if serum factors are secreted there. It could also be important in the dissemination of the disease that sometimes occurs via the bloodstream. In addition to this resistance to humoral factors, gonococci from guinea-pig chambers are more resistant than strain BS to intracellular killing by human phagocytes (Witt et al., 1976).

The results of infectivity tests in guinea pigs were considered to be more valid at $24 \mathrm{~h}$ post-inoculation, before selection or phenotypic change would have much effect. Frequently the viable count of strain $\mathrm{BS}_{3}$ in the chamber increased by $10^{4}$ to $10^{5}$ during the first $24 \mathrm{~h}$, 
indicating rapid growth with little lag phase, whereas the count of BS often fell initially and increased subsequently in those animals found to be infected after 7 days, indicating that selection of resistant types occurred.

The infectivity of the smallest inoculum of BS3 that had been kept in liquid nitrogen without loss of viability testified to the efficacy of the storage method for preserving the character of the organisms grown in vivo.

Extracts of BS3 (agar) and BS (agar) were made for gel diffusion and electrophoresis in polyacrylamide gels without appreciable lysis of the gonococci. Hence, although internal components could have been present, the extracts contained mainly easily-removed surface materials. In gel diffusion with unadsorbed and adsorbed antisera, the extract of BS3 (agar) organisms showed one or two antigens that were either absent or present to a lesser extent in the corresponding extract of BS (agar) organisms. Similarly in polyacrylamide gel electrophoresis, one or more protein components were present in the extract of Bs3 (agar) but not in that from BS (agar). These substances may be responsible for the altered biological properties of the strain grown in guinea pigs and investigations of their nature and function are in progress. Similar components have been detected in extracts from two other gonococcal isolates after guinea-pig passage suggesting that the in vivo grown Bs strain first examined was not unique in this respect.

The strain grown in vivo is different from the parent strain grown in vitro. Whether the difference arises from selection or phenotypic change or a mixture of both is a matter for future research. But clearly the parallelism of the properties of the organisms grown in guinea pigs with those of organisms from urethral pus, particularly their resistance to the bactericidins of human serum and phagocytes (Witt et al., 1976), indicate that gonococci grown in guinea pigs are a useful tool for the study of the determinants of gonococcal pathogenicity.

We thank Mrs J. Lichfield and Mr M. Cattermole for help with electron microscopy and for photography.

C.W.P. is a Beit Memorial Fellow.

\section{REFERENCES}

Amies, G. R. \& Garabedian, M. (1967). An easily prepared selective medium for the cultivation of Neisseria gonorrhoeae. British Journal of Venereal Diseases 43, I37-I 4 I.

ARko, R. J. (1972). Neisseria gonorrhoeae: experimental infection in laboratory animals. Science, New York I77, 1200-I 201 .

Kellogg, D. S., Jr, Peacock, W. L., Jr, Deacon, W. E., Brown, L. \& Pirkle, C. I. (I963). Neisseria gonorrhoeae. I. Virulence genetically linked to clonal variation. Journal of Bacteriology 85, I274I 279.

KellogG, D.S., JR, Cohen, I. R., Norins, L. C., Schroeter, A. L. \& Reising, G. (I968). Neisseria gonorrhoeae. II. Colonial variation and pathogenicity during 35 months in vitro. Journal of Bacteriology 96, 596-605.

Mahoney, J. F., Van Slyke, C. J., Cutler, J. C. \& Blum, H. L. (1946). Experimental gonococcic urethritis in human volunteers. American Journal of Syphilis, Gonorrhea and Venereal Diseases 30, I-39.

Novotny, P., Short, J. A. \& WALker, P. D. (I975). An electron-microscope study of naturally occurring and cultured cells of Neisseria gonorrhoeae. Journal of Medical Microbiology 8, 4I3-427.

Penn, C. W., Veale, D. R., Sen, D., Witt, K. A. \& Smith, H. (I975). Altered pathogenic, morphological and antigenic properties of Neisseria gonorrhoeae adapted to growth in guinea pig subcutaneous chambers. Proceedings of the Society for General Microbiology 3, 57.

SMith, H. (1972). The little-known determinants of microbial pathogenicity. Symposium of the Society for General Microbiology 22, I-24.

Veale, D. R., Smith, H., Witt, K. \& Marshall, R. B. (1975). Differential ability of colonial types of Neisseria gonorrhoeae to produce infection and an inflammatory response in subcutaneous perforated plastic chambers in guinea pigs and rabbits. Journal of Medical Microbiology 8, 325-335. 
Veale, D. R., Witt, K., Finch, H. \& Smith, H. (1976). Penetration of penicillin into human phagocytes containing Neisseria gonorrhoeae: intracellular survival and growth at optimum concentrations of antibiotic. Journal of General Microbiology 95, 353-363.

WARD, M. E. \& WATT, P. J. (I97I). The preservation of gonococci in liquid nitrogen. Journal of Clinical Pathology 24, I 22-I23.

WARD, M. E., WATT, P. J. \& GlynN, A. A. (1970). Gonococci in urethral exudates possess a virulence factor lost on subculture. Nature, London 227, 382-384.

Witt, K., Veale, D. R., Finch, H., Penn, C. W., Sen, D. \& Smith, H. (1976). Resistance of Neisseria gonorrhoeae grown in vivo to ingestion and digestion by phagocytes of human blood. Journal of General Microbiology 96, 34I-350. 